\title{
Study on Anti-seismic Strengthening of the Ancient Stone Archway
}

\author{
Ding ZHANG ${ }^{1, \mathrm{a}}, \mathrm{Ze}-$ Y un WANG ${ }^{2, \mathrm{~b}}$ and Yan-Xia LIANG ${ }^{3, \mathrm{c}}$ \\ ${ }^{123}$ Xihua University,Chengdu Sichuan China 610039 \\ a aceallse@sina.com', bjzytmw@126.com, ${ }^{\mathrm{c}} 794162867 @ q q . c o m$
}

\begin{abstract}
Chinese ancient stone archways are in flat structure. And joints of their members are of half tenons and mortises. Under the influence of the earthquake, the resisting ability of archway's uneven sides is relatively poor and the relevant members have little reliable joints. This paper is to analyze seismic strengthening feasibility of Tiantai mountain stone archway which is damaged from the earthquake and to research on the aspects of the loading mode, structure layout and soundness. On the premise of guaranteeing the authenticity and beauty, we use earthquake damaging mechanism of stone archways and the modern anti-seismic structure designing theory and modern building materials. We also follow the way of the modern construction technology and ancient construction and strengthen the anti-seismic way of the resisting ability of Tiantai mountain stone archway's uneven sides and joints of tenons and mortises. The best anti-seismic strengthening schemes are put forward as well.
\end{abstract}

\section{Introduction}

Archway is a kind of open-type landmark composed by single or multiple rows of pillars and lateral frontal squares in traditional Chinese architecture. The early origin of the archway always can be traced back to before the history of the Qin Dynasty and Han Dynasty. The most prosperous time is in Ming Dynasty and Qing Dynasty, and it still has strong vitality after thousands of years. Sitting west to the east, Tiantai mountain stone archway is a part of Yongle Temple. It belongs to Preserving Artifacts since it has been built for hundreds of years. Because of its long history and some historical reasons, its main body has suffered natural and human influence so that some damages which threat its safety are discovered. For example, on May $12^{\text {th }}$, when the Wenchuan earthquake occurred, its body was broken and anti-seismic enforcement was not placed on the agenda though the main body was once repaired emergently. In addition, the main body was severely damaged during Lushan earthquake on April $20^{\text {th }}$ in 2013 and emergent repair was necessary.

\footnotetext{
* Corresponding author:aceallse@sina.com
} 


\section{The Current Damaged Situation of the Stone Archway}

Tiantai mountain stone archway which is on the same central axis with Yongle Temple hall is located in Tiantai Town, Qionglai County, Chengdu City of Sichuan Province. With the use of sandstone material, the stone archway has four columns and three rooms double-hipped roof structure and enjoys bracket system imitating timberwork. The height is 8.65 meters and the width is 9.65 meters. The horizontal inscribed board says Beautiful Landscape of Study Nest and the First Buddhist Temple on the front and back respectively. The mould of stone archway is shown in Figure 1. In the east of the stone archway red sandstone. It is 10.60 meters wide, 5.15 meters tall and 0.83 meters is a screen wall of thick. The screen wall consists of a seat, a wall body and a coping. The seat is ancient but generous. It has succinct lines. Carving Kirin designs on the north wall body center are very vivid. The coping has three intermittent roofs with stone pantile style. On the west side of the stone archway, there are two red sand carving stone lions. The lion sits on the north side and the lioness sits on the south side. And they are staring at each other.

Roads and drainage system next to the stone archway are intact. Influenced by " 4.20 " earthquake, part of the rigid floor slab case become warped, several rails fracture and collapse and local stepping stone loosen and shift. Cultural relics are surrounded by farmland and green lands. The hard peripheral places of the stone archway, especially the drain are thick with weeds which have certain effects on the drainage. The stone archway base is flat and stored intactly. But it has a few local lack of angles and edges and is slightly weathered. At the bottom of the base board, there are many weeds, moss and mold. The base status diagram is shown in Figure 2. The stone surface is slightly weathered. Pillars on the west side are slightly tilted.The overall situation is good which does not affect the bearing. Clamp rod stones' surface is weathered. Joints of clamp lever stones and pillars have different cracking to some extent. The upper one is wider than the lower one which widest point reaches 4 to 6 $\mathrm{cm}$. Clamping bar pillars' and stones' joint is shown in Figure 3. The joints of stone frames and pillars have cracked and mortise tenons' joints have connected loosely. Part of QT construction has a phenomenon of losing tenons. One of QT construction on the north side is lost. The current situation of stone frames and QT construction is shown in Figure 4. The bucket archway is basically intact and slightly weathered. The red sand stone carving pantile style roof is damaged seriously. The ridge of it crazes in many parts and angles are destroyed and lost.

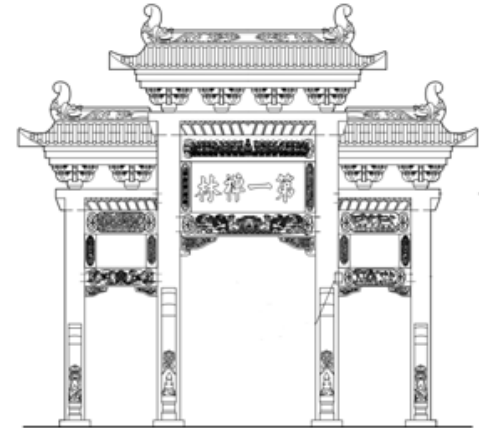

Fig. 1 The west side of the stone archway

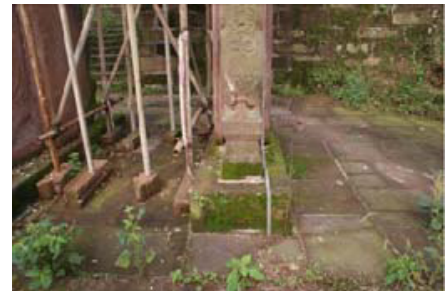

Fig. 2 The base of the stong archway 


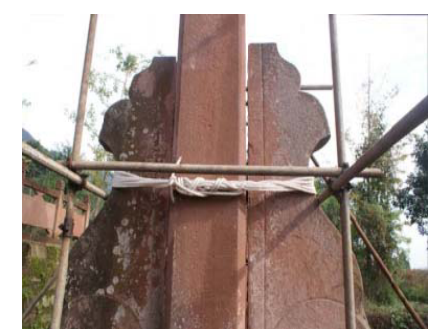

Fig.3 Clamping bar pillars' and stones' joint

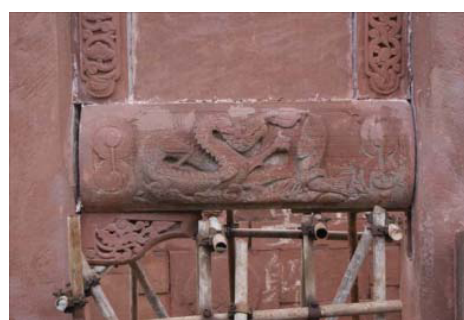

Fig. 4 The current situation of stone frames and QT construction

\section{The Formation of The Stone Archway and Analysis of Seismic Mechanism}

Chinese traditional ancient buildings are mostly made of wood. The ancient stone archway is similar to wood in the aspects of building structures and structural styles. The ancient stone archway is made of stones, so it is very heavy. And it is low, so the force bearing area of it is in a small size. The stone archway can bear more wind than the wood archways. From the point of structural styles, stone archway is of beam and column construction, which is similar to bent structures in modern buildings. Because of the very flat structure in the stone archway, the resisting ability of archway's uneven sides is relatively poor. On both sides of the pillars of the ancient stone archway uses clamp rod stones or drum-shaped bearing stones as a diagonal bracing. Through the bracing, the archway strengthen its out-plane horizontal force and stability. When the earthquake comes, the diagonal bracing may be damaged due to resisting of out-plane seismic action. Stone archway's pedestal is directly put on the rigid ground or the hard soil, which does not have any connection with the base below. With the change of the surrounding environment, the archway is easy to have the uneven settlement of foundation. The pedestal and the base are in a sliding system, so they have great friction, which can be used as the hinged structure. Under the effect of horizontal and vertical earthquake, the stone archway's pedestal and base may have relative sliding.

The ancient stone bucket archway supports the upper pick eaves, which have the supporting effect to the roof. At the same time, it puts the weight of the roof down to the post and then the ground, which reduces the pressure on archways and helps to increase the width between archways. The stone structure is shown in Figure 5.

When the earthquake comes, brackets of the archway expend much energy because of their elastic deformation and friction sliding. And brackets of the archway make a vibration buffer layer between the roof and the column frames, which reduce the damage of ancient building structures. But when the load reaches a certain extent, the archway brackets' bearing capacity reaches to the ultimate and will cause destruction. QT construction shortens the net span of stones and restrains stones' bending deformation to some extent, which reduces the shearing force between stones and columns and increases stiffness among stones and enhances the load-bearing ability of stones. QT construction has strengthened structures' integrity in the force deformation and has increased mortise-tenon joints' rotational stiffness. What's more, QT construction has reinforced beams' and columns' joints and has reduced stones' noise immunity and has increased structures' ductility. And the construction also has the function of preventing horizontal and vertical members sloping like modern brackets. Because of the long time, columns and QT construction have partly weathered. The joints go loose and QT construction's load-bearing and binding capacity to stone frames go worse. When it comes to the earthquake, QT construction may be damaged under the effect of load-bearing repeatedly. 
Straight tenons are often used in ancient buildings. This connection is bigger than rigid connection in deformation but smaller than hinged connection, so it is semi-rigid connection. Straight tenons expert in flexural and shear properties, but they are poor in tensile pulling resistance. Straight mortises' joint bending parts are small when they meet the earthquake. The resistance to bending parts mainly rely on the static friction force between their mouth and tenons. With the increase of bending parts, tenons and their mouth have relative displacement. Tenons and the mouth squeeze each other. To balance the bending parts, tenons roots will sustain great tensile stress. Under the repeating effect of the earthquake, tenons gradually uproot from the mouth. The rigidity of tenons' and mouth's points degrade which can damage the points. Archways' frames are put on columns. The tenons of joint parts use semi-penetrated mortises. The structure of these mortises is shown as Figure 6. Because of the short joint length of semipermeable tenons and un-elastic stones, tenons damage easily when the earthquake comes. And this may cause a loss of reliable connection among archways artifacts and then damage the whole structure.

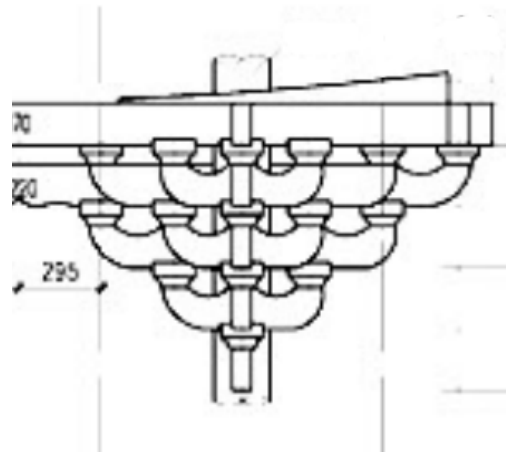

Fig. 5 Structure of bucket archway

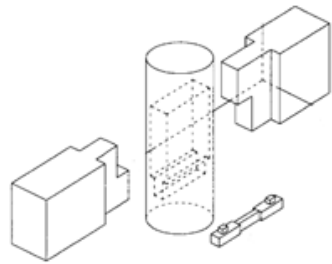

Fig. 6: semi-penetrated mortises

\section{Seismic Strengthening and Renovation Plan of the Stone Archway}

Clamping bar pillars and stone joints have both different cracking. The cracking of upper ones are wider than the lower ones, which has 4 to 6 centimeters in the widest. The stripping gap is filled up with mud and dust. It is difficult to ensure reinforcement effect of grouting from the outside, therefore we remove the clamp rod stone and remove dust and debris faced to pillars. On the contacting surface, we coat it with a layer of epoxy resin adhesive and fix it firmly with the iron clamp and wooden sticks. In addition to the use of modified epoxy adhesive reinforcement, we also use $2 \mathrm{HRB} 335$ steel bars of $10 \mathrm{~cm}$ long and diameter of 12 $\mathrm{mm}$ to reinforce. With a diameter of $12 \mathrm{~mm}$ electric drill, we punch from the side. And the anchor hole is $2 \sim 5^{\circ}$ down and $10.5 \mathrm{~cm}$ deep. After the dust removal in the hole, we use epoxy slurry to wet the anchor hole. Then we fill up the hole to $4 / 5$ of the volume with epoxy mastic and insert with steel bars by external forces (Steel bars should be done in anti-rust processing before inserting and be coated with a layer of epoxy slurry on the surface) and re-joint with putty on the surface finally.

The joints of stone frames and pillars have cracked and mortise tenons' joints have connected loosely. In the joint connection of stone frames and pillars' mortise tenons, we put the bar into it to have auxiliary connection. Iron components have more flexibility and strength than stones, thus they have strengthened the connection strength among the stone artifacts. And they also have increased the elastic connection between pillars of stone memorial archways and stone frames, which make stone memorial archways can bear a 
certain amount of local deformation and local displacement. Under the archway columns on both sides of stone archways, we put stirrup. And we put rubber gasket between stirrup and stone columns. The outer ring is made of galvanized steel strip in $40 \mathrm{~mm} * 3 \mathrm{~mm}$ and basket screw structure to ensure the integrity of stone archways which can increase the ring's resistance when the earthquake comes.

QT construction has a phenomenon of losing tenons. We clean the soil, cement, moss in the seam and do the pointing with putty. When north QT lost, we supplement it with new components. Varieties, texture and color of selected stone members should be similar to the original. The dimensions and making ways are consistent with the original. With the steel reinforcement method, we embed anchors in QT construction in order to contact QT construction and pillars well.

\section{Summary}

The renovation and protection of ancient buildings is social. It is the same with culture, which embodies the most complete human wisdom in the environment. This thesis' fundamental viewpoint is practical engineering. Based on maintaining the original cultural relics, the loading mode, structure layout and soundness of cultural relics which need to be repaired are reasonable through the analysis and research of ancient stone archways' structure layout, structure loading and structure form. And the thesis is accord with the requirement of modern urban construction and the current specification. What's more, it combines the modern construction technology with ancient construction technology and materials. It also follows the principle of "repair the old as the ancient ones and do not change the original appearance" to repair and reinforce ancient buildings.

\section{Acknowledgement}

Supported by the Innovation Fund of Postgraduate,Xihua University.

\section{References}

1. Fang Don -bing, Miyamotoe Y, 1wasaki S, Deto H, et a1.Dynamic characteristics of a chinese architectural heritage.In : $\mathrm{P}$ resented at the International Symposium on Stuctural Preservation of the Architectural Heritage, Rome, Italy ,1993.

2. Song $\mathrm{Fu}$, Feng Xiang,Cun Hai.Experimental investigation on Que Ti for improving mechanical properties of wooden beam [J].Engineering Mechanics(supplement),2003,399-402

3. Fang D P, Iwasaki S, Yu M H, et al. Ancient Chinese timber architecture- I : Experimental study [ J ] . Journal of Structural Engineering, 2001, 127(11):13481357.

4. Fang D P, Iwasaki S, YU M H, et al. Ancient Chinese timber architecture- II : Dynamic characteristics [ J ] . Journal of Structural Engineering, 2001, 127 ( 11 ):1358- 1364.

5. Lee Y W, Hong S G, Bae B S, et al. Experiments and analysis of the traditional wood structural frame [C] 14th World Conference of Earthquake Engineering, Bei-jing: 2008. 